\title{
Arquitetura popular afro-brasileira
}

\author{
Gunter Weimer \\ Doutor; Universidade Federal do Rio Grande do Sul, Porto Alegre, RS, Brasil; \\ gunterweimer@gmail.com
}

\begin{abstract}
Resumo: A arquitetura africana tem uma história multimilenária que, até hoje, tem sido pouco estudada. Em sua grande diversidade de manifestações, apenas uma parte foi trazida para o Brasil devido à égide de preconceitos existentes no período do comércio escravista. Por esta razão examinam-se as diretrizes principais das culturas banto e sudanesa. Como no período colonial a população de origem africana era majoritária, sua arquitetura se tornou hegemônica nos estratos populares, apesar das influências das culturas indígenas e lusitana. Através deste mecanismo, ela desenvolveu uma grande capacidade de adaptação.
\end{abstract}

Palavras chave: Arquitetura popular. Arquitetura afro-brasileira. Arquitetura vernacular.

\section{Introdução}

O presente trabalho pretende mostrar que o Brasil se beneficiou de uma milenária tradição arquitetônica africana que foi trazida por arquitetos escravizados e que se tornou hegemônica nas camadas populares brasileira. A convivência de culturas heterogêneas fomentou a formação de procedimentos construtivos que, através de adaptações e ajustamentos nem sempre pacíficos, criaram formas peculiares de expressão arquitetônicas adequadas aos diversos meios ambientes do país, desde o semiárido até o super úmido.

Dada a escassez de referências bibliográficas sobre o tema, o presente trabalho resultou de pesquisas de campo em 24 Estados do Brasil ao longo de nossa vida profissional. A documentação assim levantada foi confrontada com bibliografias internacionais que foram complementadas com quatro viagens à África. Uma revisão de textos produzidos no período colonial, com destaque para os do século XVIII, permitiu realizar um exame abrangente da evolução da arquitetura dessa matriz, com suas óbvias influências tanto da parte de indígenas

Em Questão, Porto Alegre, v. 26, p. 291-316, Edição Especial Dossiê Patrimônio e Culturas Tradicionais, 2020 doi: http://dx.doi.org/10.19132/1808-5245260.291-316 
como dos conquistadores. Para marcos temporais foi fixado o período entre o início da colonização até a abolição da escravatura.

Desde logo, deve ser assinalado que, como em todas as sociedades, apresenta-se uma dicotomia caracterizada por realizações destinadas à elite social, dita erudita, em oposição com a realizada pelas e para o uso das massas populares. Como a presença da elite africana no Brasil foi apenas esporádica e passageira, sua arquitetura aqui não deixou presença. Por isso, ela não foi considerada ao contrário de suas formas populares que deixaram herança em todo o território nacional (WEIMER, 2012; WEIMER, 2014).

De início convém assinalar que o continente africano é quase duas vezes maior do que a América do Sul. Apesar de possuir vastas áreas desérticas, tem uma população 2,3 vezes maior. Isso significa que sua população apresenta uma densidade muito maior que a nossa e está mais uniformemente distribuída, por ser majoritariamente em região rural. Seu território tem sido dividido em África Branca, devido à sua população de provável origem do Oriente Próximo que ocupa a faixa entre o Saara e o Mar Mediterrâneo com alguns enclaves na África subsaariana, enquanto o restante do continente tem sido denominado de África Negra, decorrente da cor mais escura de sua população. Porém na parte oriental da Ilha de Madagáscar há um forte contingente de população malaia que a ocupa desde o século $\mathrm{V}$ da era cristã.

Uma das características de uma cultura é a língua falada por determinado contingente populacional. Conforme dados de linguistas, na África Negra são falados mais de duzentos idiomas, o que significa que deve existir igual número de tradições culturais e arquitetônicas. Segundo os etnólogos, essa população é dividida em oito grandes linhagens culturais: os nilotas estão estabelecidos no Alto Nilo; os hamitas, que ocupam o chamado corno da África (Eritréia, Somália, Etiópia); os nilota-hamitas que se caracteriza por ser uma população influenciada pelas duas linhagens anteriores e que habitam a região dos grandes lagos; os sudaneses, ocupantes da grande floresta equatorial; os bantos, da parte meridional do continente; os bacas, conhecidos no mundo ocidental pelo designativo pejorativo de pigmeus e moradores no norte do Congo, entre território de sudaneses e bantos; os koikoi e os sam, conhecidos como hotentotes 
e bosquímanas respectivamente, que formavam, segundo os geneticistas, o contingente primordial da população africana. Hoje estão reduzidos a pequenos grupos que ocupam os lados ocidental e oriental do deserto da Namíbia.

Dessas linhagens, as três primeiras não têm interesse para a arquitetura brasileira, pois se situavam em lugares distantes e pouco propícios ao acesso dos navios negreiros. Os bacas, koikoi e sam também não foram trazidos para a América, por serem de pequena estatura e, consequentemente, não servirem para o trabalho, segundo os preconceitos racistas dos escravocratas. Portanto, os fornecedores de mão-de-obra foram, inicialmente, os bantos (KARASCH, 1987; STÖRIG, 2003) e depois que escassearam as populações costeiras de Moçambique e entre Angola e Camarões, foram trazidos os sudaneses da costa entre Gâmbia e Nigéria.

\section{Os bantos}

Os maiores fornecedores de escravos foram Angola e Moçambique onde, nos atuais países, são faladas, respectivamente, 13 e 14 línguas oficiais, além do português, que serve de língua de trânsito, condição que está perdendo para o suazi que está se expandindo rapidamente. E cada uma dessas línguas apresenta variantes dialetais, o que equivale a diversidade cultural. $O$ fato de que a maioria dos migrantes era proveniente de populações costeiras veio a facilitar nossos estudos.

Esta região é conhecida pela exuberância da variedade de sua fauna o que se contrapunha à limitada variedade de suas essências vegetais. A existência de um limitado número de espécies de árvores não favoreceu o desenvolvimento da carpintaria e, desse modo, o emprego da madeira se limitou a dar sustentação ao barro e à cobertura.

A tipologia mais comum das construções dos bantos era a de cone-sobrecilindros ou semiesfera-sobre-cilindro (Figura 1). O piso era majoritariamente de chão batido. O material de construção mais comum era o barro (BARDOU; ARZOUMANIAN, 1979). A técnica de construção preferencial era a taipa, que consistia na preparação de uma "rede" de galhos entrelaçados e/ou amarrados que servia de sustentação do barro devidamente preparado que era aplicado 
pelos dois lados. A par desta construção era montada a cobertura junto ao canteiro e consistia de uma armação de galhos encaixados e/ou amarrados sobre a qual era afixada uma camada de capim. Depois que as paredes tinham secado, a cobertura era fixada sobre as mesmas.

Figura 1 - Algumas tipologias da arquitetura popular angolana

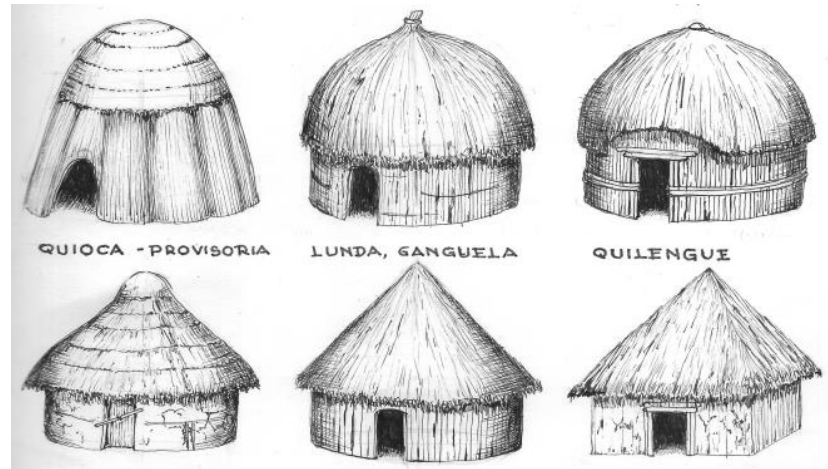

Fonte: Weimer (2014, p. 113).

Cada construção tinha normalmente uma só porta, ou duas, quando cada uma era de uso de um dos sexos. Embora com clima quente, o uso de janelas era desconhecido, e a ventilação se fazia por meio de um rasgo contínuo entre a parede e a cobertura. Essa solução favorecia a aeração do ambiente interno independentemente da direção do vento. Em locais de ambientes úmidos, essas construções eram colocadas sobre plataformas de terra, numa espessura em que a ascensão da água por capilaridade era neutralizada pela força da gravidade. Outra forma de atenuar a inclemência do calor era construir beirados salientes ou, melhor ainda, prover as construções de varandas.

O conceito de habitação diferia muito da tradição europeia. Cada construção, chamada de cubata em língua quimbundo, se destinava a uma só função. Uma moradia era composta por várias dessas unidades, que eram dispostas de modo a permitir ma ventilação mais favorável. A cozinha, em geral, era protegida apenas por uma cobertura horizontal. O conjunto dessas cubatas formava uma epata (Figura 2), cujo tamanho variava de acordo com as posses de seu dono. Como a sociedade era poligâmica, havia uma cubata para cada uma das esposas e, como havia um número razoável de homens solteiros por imposição do sistema, havia a necessidade de abrigar agregados da parentela. 
Uma tipologia relativamente rara era a cubata de mukambu (isto é, de cumeeira, portanto de duas águas) que no Brasil recebeu o nome de mocambo.

Figura 2 - Esquema de uma epata banto

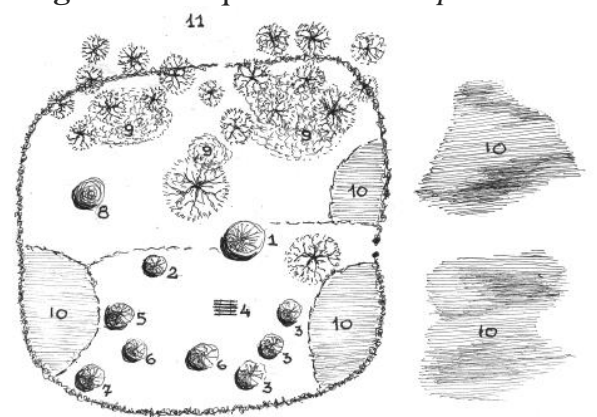

Fonte: Elaborada pelo autor.

Legenda: 1-Marido; 2-Matriarca; 3-Esposas; 4-Cozinha; 5-Visita; 6-Parentela; 7-Sanitário; 8Celeiro; 9-Animais; 10- Plantação; 12-Pastoreio.

Fisicamente, uma epata era demarcada por um cercado de contorno que apresentava as mais variadas soluções (Figuras 3 a 6), que poderiam ser cercasvivas (em geral, de agaves e/ou urtigas), de galhos, de euphorbia (planta similar ao cacto americano) (figuras 3 a 6), trançados de bambus (querindim), de taipa, de pedra, de pau a tique, paliçada, dentre outras. Conforme a cultura, uma epata podia conter um abrigo noturno para o gado, uma horta e/ou árvores frutíferas. O sistema poligâmico, na forma como era praticado entre os bantos, fazia com que houvesse certa resistência à formação de aldeias.

Figuras 3 a 6 - Tipos de cercados de contorno

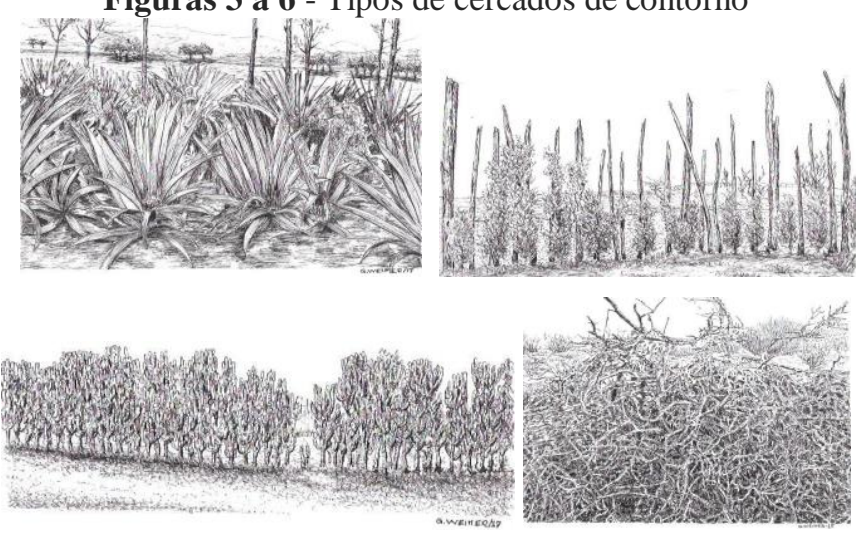

Fonte: Elaboradas pelo autor.

Nota: Da esquerda para direita, de cima para baixo: agave, euphorbia, urtigas com pau-a-pique e arbusto típico local.

Em Questão, Porto Alegre, v. 26, p. 291-316, Edição Especial Dossiê Patrimônio e Culturas Tradicionais, 2020 doi: http://dx.doi.org/10.19132/1808-5245260.291-316 
A justaposição de várias epatas formava um kilombo, ou uma aldeia. Este termo foi adotado no Brasil, porém com um sentido deformado por imposição do sistema escravocrata. Se na África o termo designava apenas uma aldeia, aqui acabou por receber a conotação de um lugar escondido, fortificado, onde se reuniam os negros fugidos.

Aos se formarem, os kilombos apresentavam um espaço aberto centralizado (praça) ao redor do qual eram construídas as diversas epatas, conservando, todavia, uma organização plástica e hierárquica característica da tradição construtiva de cada povo.

Figuras 7 e 8 - Dois quilombos de Quênia, quicuio e quivaiju, respectivamente
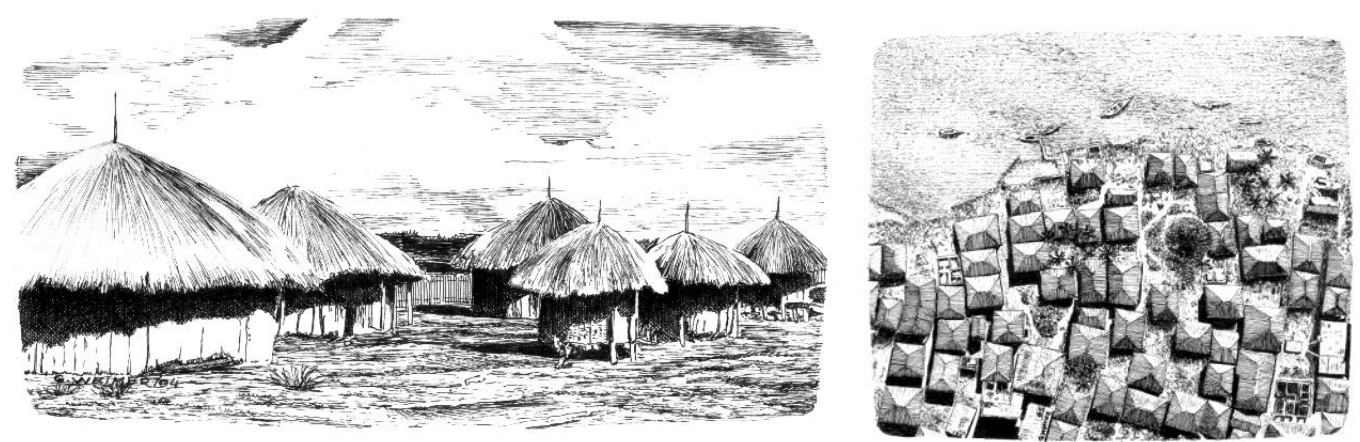

Fonte: Weimer (2014, p. 148).

Uma forma especial de epata é chamada de sanzala, que no Brasil deu origem à palavra senzala. Peculiar dos povos litorâneos entre Cabinda e o sul de Camarões, a sua característica principal é a formação de duas fileiras de cubatas geminadas, cada qual abrigando uma metade da tribo. Cada uma dessas filas de casas geminadas pertenciam aos vários clãs que a compunham.

Figura 9 - Uma sanzala fang, do Gabão

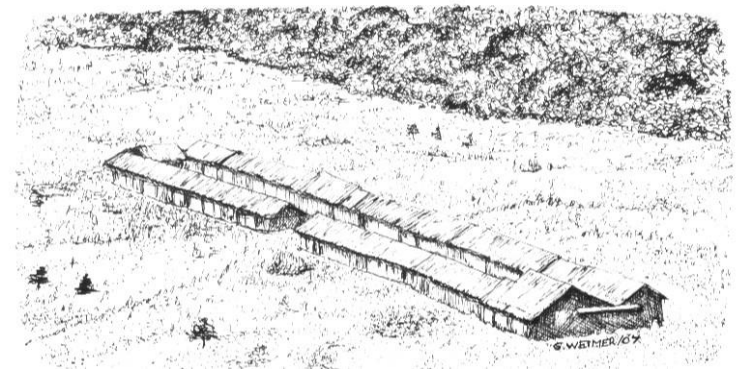

Fonte: Weimer (2014, p. 146).

Em Questão, Porto Alegre, v. 26, p. 291-316, Edição Especial Dossiê Patrimônio e Culturas Tradicionais, 2020 
Se havia certa resistência à formação de quilombos, isso se tornava ainda mais evidente em relação à formação de cidades. Como a organização social estava estruturada em base tribal, cada cidade era composta por diversos mисеques (bairros), cada qual abrigando os membros de uma determinada tribo. Em decorrência, cada muceque apresentava características próprias, e cada um se separava dos demais fisicamente, por terrenos desocupados, por acidentes do terreno ou, eventualmente, por altos muros (figura 10). Os habitantes de cada mисеque tinham língua, costumes, regras de convivência e vestimentas próprios. Em consequência, a arquitetura também apresentava características singulares a cada grupo. Semelhante à formação dos quilombos, cada muceque apresentava uma praça central, que se constituía no espaço político, que era definido por uma cubata de sombra, ou seja, prédio em que se reuniam os homens em assembleia, junto à qual ficava a residência do soba (prefeito do bairro).

Figura 10 - Parte da cidade do Cabo, África do Sul, mostrando os diversos bairros separados entre si

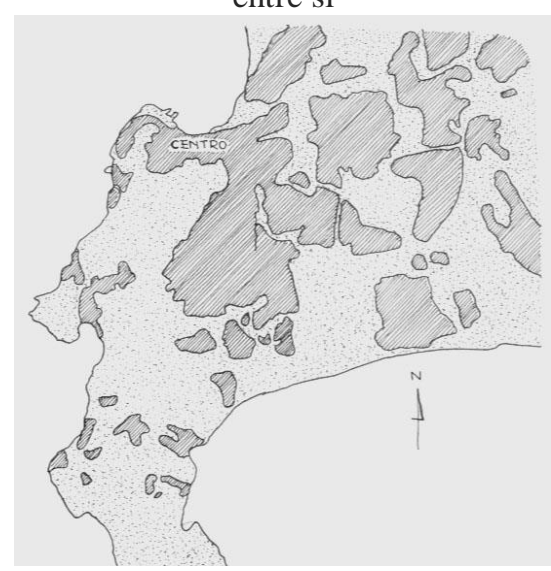

Fonte: Weimer (2014, p. 151).

Uma característica peculiar dos bantos e que tem causado alguma confusão no Brasil, é o fato de que não possuíam um espaço comunitário próprio para a prática do culto religioso, ao contrário dos sudaneses. Sua prática era doméstica e realizada dentro de cada cubata, onde havia uma espécie de altar em que eram expostos objetos referentes às suas deidades, em geral ligadas aos ancestrais do grupo familiar. 


\section{Os sudaneses}

Os sudaneses ocupavam uma longa faixa de terra delimitada no sentido norte-sul pela Saara e Oceano Atlântico e se estendia no sentido leste-, desde a região dos grandes lagos até o Atlântico. Fisicamente são mais longilíneos e apresentam uma tez mais escura que os bantos, uma vez que estes últimos desde muito tempo mantiveram contatos com os povos da África Branca, dos quais sofreram influências. Em razão disso, os sudaneses foram considerados, erroneamente, e equivocadamente, como sendo mais evoluídos do que os bantos. O motivo desse preconceito se deve ao fato de que seus aldeamentos e cidades têm uma forma mais aproximada da europeia.

À semelhança dos bantos, suas construções, ditas sarsunumas, expressão própria da língua dos befadas para designar as construções dos sudaneses que corresponde às cubatas dos bantos, embora ambas tenham aspectos próprios e particulares. Elas são monofuncionais, ou seja, destinadas a uma única função como dormitório, cozinha, etc.

Em geral, são muito decoradas com relevos ou pinturas (Figuras 10 a 12). O conjunto dessas construções tem sido denominado de morança (similar a uma casa) e as aldeias formadas por alas, de tabanca. Suas morfologias são muito variadas devido à diversidade dos ambientes ecológicos. A transição entre a floresta equatorial e o Saara propicia a formação de três ambientes diversos. Ao longo do deserto surgiram as chamadas "casas-castelo" (Figura 13) onde as sarsunamas apresentam mais de um piso, o que é raro na arquitetura africana. Entre elas, era levantada uma alta parede de taipa. Dessa forma, os ventos muito quentes do deserto passavam por cima das mesmas, afetando minimamente o ar mais frio, e por isso mais pesado, existente no pátio interno e dentro das construções. Por viver num clima semidesértico, a população tinha grandes dificuldades de sobrevivência e sua pobreza fazia com que as construções fossem muito simples e de acabamento escorreito. 
Figuras 11, 12 e 13 - Fachadas da moradia do emir de Ziender, de uma casa ibo e interior de uma casa ghadami
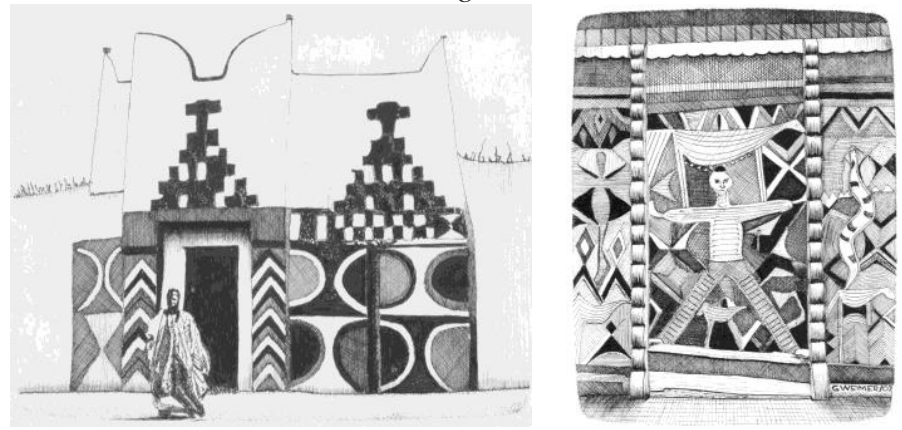

Fonte: Weimer (2014, p. 52; 2004, p. 77).

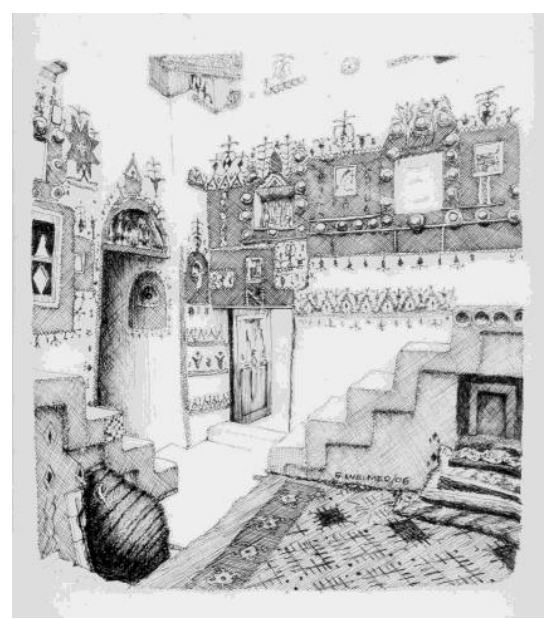

Fonte: Elaborada pelo autor.

$\mathrm{Na}$ faixa média entre o deserto e o oceano predominava a savana, com influências do deserto menos marcantes. A divisão de suas tabancas era semelhante às das casas-castelo, porém suas sarsunumas tinham um só piso e eram mais elaboradas, com um acabamento em relevo ou com pintura. Os muros entre as diversas construções unitárias eram de meia altura e formavam um pátio mais requintado em seu acabamento. Esse tipo de tabancas tem sido denominado de casa-pátio (Figuras 15 e 16). Ao que consta, essas duas formas de tabancas não tiveram influência na arquitetura do Brasil, porque os imigrantes vieram da faixa costeira. 
Figuras 14, 15 e 16 - Uma casa-castelo e uma casa-pátio, de Benim e o interior de uma casapátio de Gana

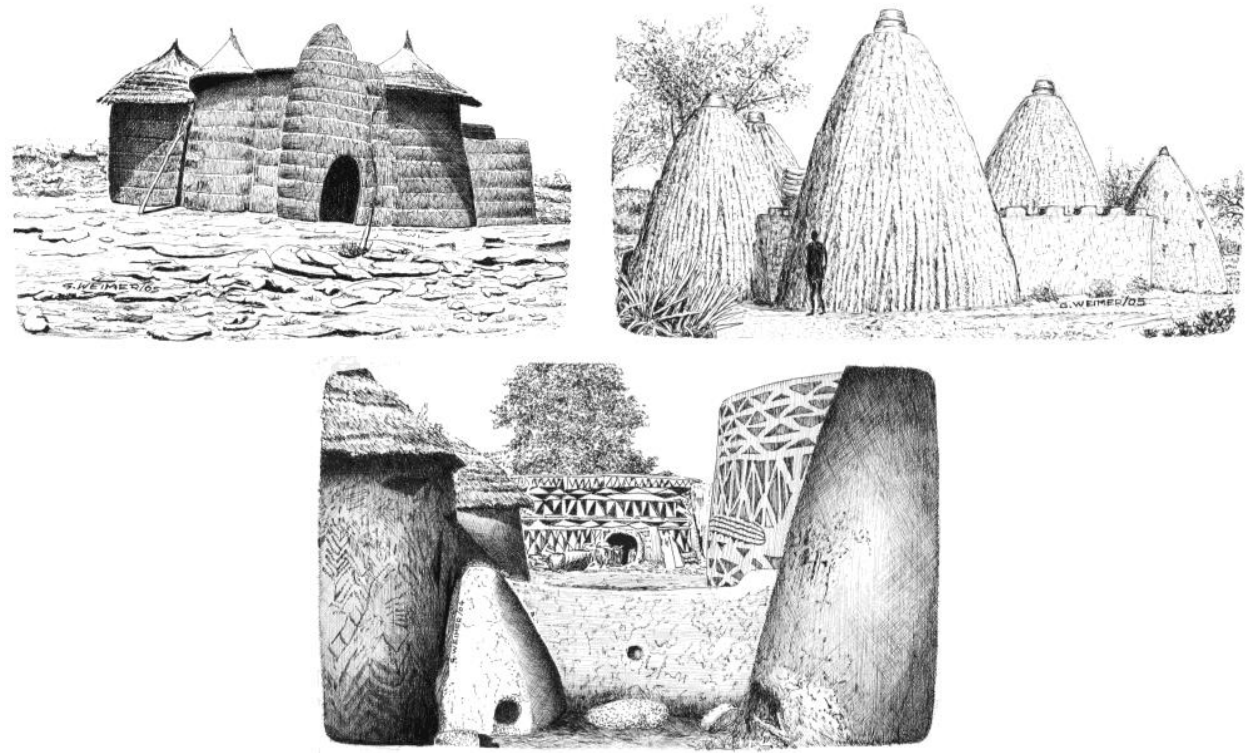

Fonte: Weimer (2014, p. 50; p. 47; p. 48).

A faixa junto ao oceano se caracterizava por possuir uma floresta densa semelhante à da Amazônia, com um clima úmido, com muitos mangues e pântanos, lagos e lagunas, rios e córregos. As regiões inundadas propiciaram a existência de aldeias e cidades inteiras construídas sobre palafitas (Figuras 17 e 18). As altas temperaturas eram atenuadas na medida em que a energia solar aquecia a água e a convertida em vapor. Um complexo sistema de passarelas para pedestres e de vias aquáticas para canoas com regras de trânsito apropriadas ordenava o deslocamento urbano.

Figuras 17 e 18 - Tabancas lacustres de Tofinou e de Ganviê, no Benim

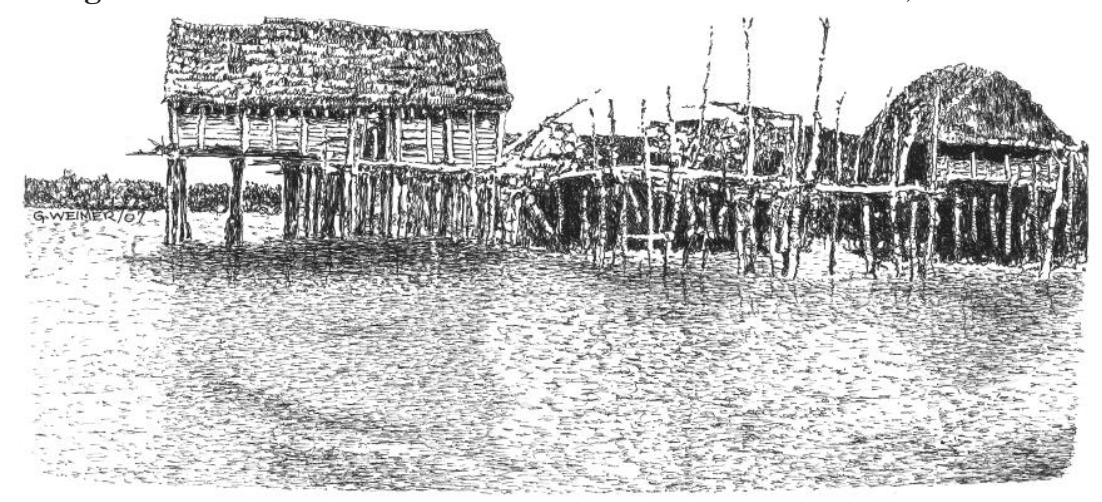

Em Questão, Porto Alegre, v. 26, p. 291-316, Edição Especial Dossiê Patrimônio e Culturas Tradicionais, 2020 doi: http://dx.doi.org/10.19132/1808-5245260.291-316 

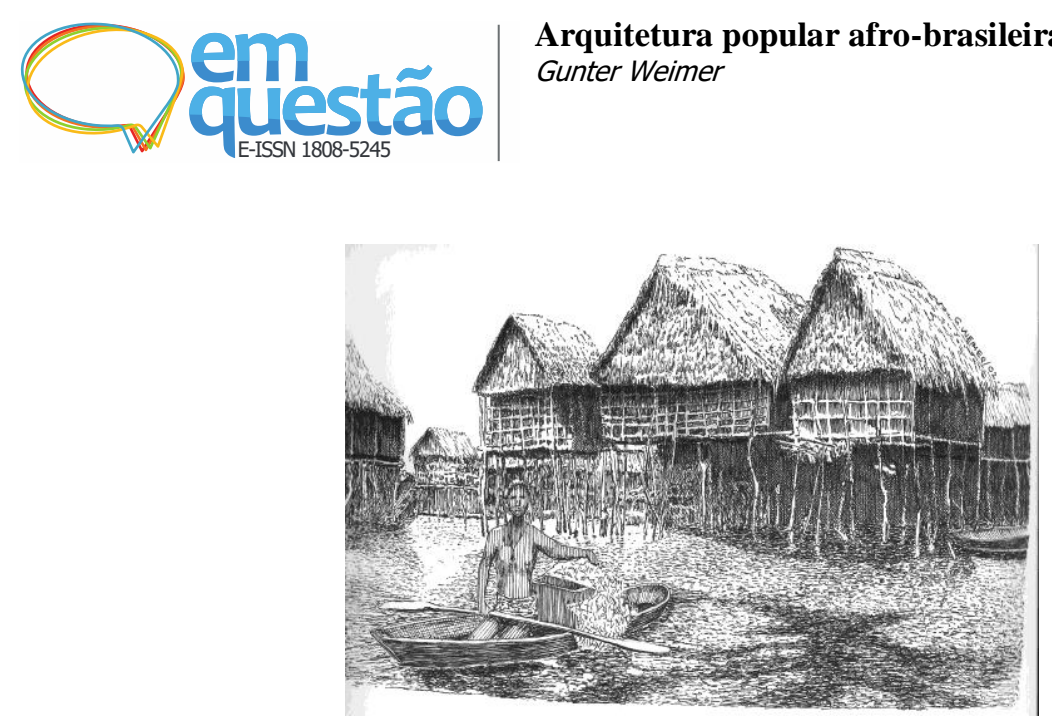

Fonte: Weimer (2014, p. 86).

A construção dessas palafitas requeria técnicas específicas. Tanto as passarelas como o piso das casas eram feitos de troncos a palmeiras fendidas. Como um piso assim construído apresentava irregularidades difíceis de serem saneadas devido à dureza das fibras da palmeira, ele era coberto por uma manta confeccionada com o cerne batido da palmeira. Em geral as paredes eram de bambu não embarrado e a cobertura era feita com folhas de palmeira.

A população que vivia em terra firme construía suas moradias em árvores altas, onde ficava abrigada. A umidade exigia que essas moradias fossem feitas em plataformas bem altas, a fim de evitar a penetração da água por capilaridade. Desse modo, os partidos arquitetônicos tinham um formato livre e aberto. As tabancas eram, basicamente, de dois tipos: as que eram construídas ao lado de uma via de comunicação (Figura 19) e aquelas em que a via passava pelo meio da povoação (Figura 20). Em sua formatação, seu desenho de aproximava das concepções das aldeias europeias, na medida em que, em geral, apresentavam uma praça central com algum destaque para o prédio governamental ou moradia da pessoa mais importante do grupo, enquanto o cemitério, as instalações sanitárias e os locais de culto se situavam na periferia do complexo urbano. Vias secundárias levavam às terras onde era praticada a agricultura, que prevalecia sobre a pecuária.

Em Questão, Porto Alegre, v. 26, p. 291-316, Edição Especial Dossiê Patrimônio e Culturas Tradicionais, 2020 


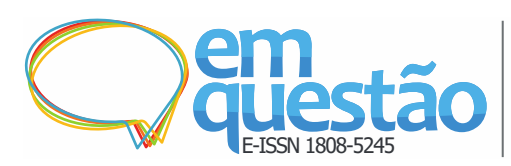

Figuras 19 e 20 - Duas tabancas, uma, de cultura mo e outra, achanti
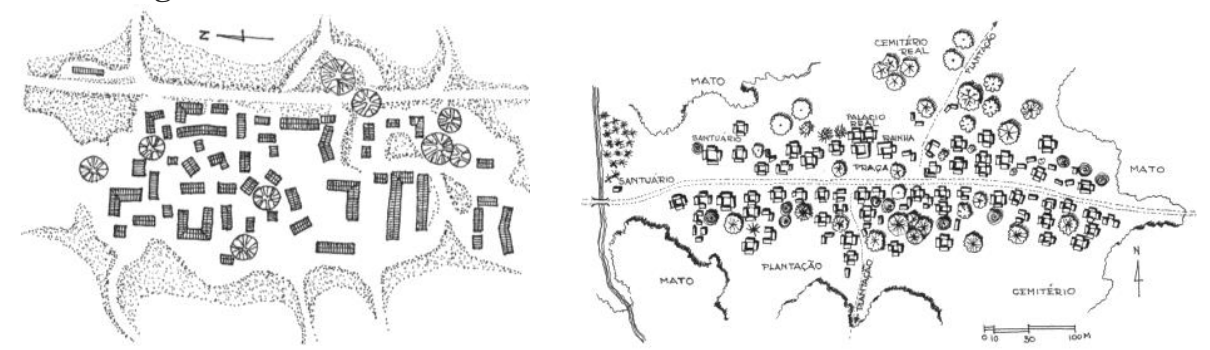

Fonte: Weimer (2014, p. 96; p. 98).

Destaque especial era dado ao santuário, que se caracterizava por apresentar um terreiro limpo, de terra batida, onde eram realizados os rituais. Junto a ele havia um número reduzido de templetes, onde eram guardadas as vestes dos orixás que ornavam os cavalos do santo durante as sessões. Ao contrário do Brasil, os orixás cultuados em cada tabanca eram em número limitado. Todavia, isso não excluía a devoção dos demais orixás, materializada no conjunto de árvores de diversas espécies, cada uma delas destinada à moradia de um orixá específico e, em razão disso, os locais de culto eram denominados de bosques sagrados.

A existência de uma rede de relações políticas entre as diversas tabancas evoluiu para sua diversificação funcional. Isso fez com que surgissem especificidades, como aldeias de peregrinação, de populações especializadas no cultivo de determinadas culturas, de pessoas peritas em determinados artesanatos, etc.

A organização social divergia da dos bantos. A estrutura poligâmica era feita para permitir que os homens poderosos mantivessem suas respectivas mulheres em locais diferentes e, preferencialmente, distantes entre si. Isso fazia com que eles se deslocassem de tempos em tempos, para a convivência com cada uma de suas esposas, e, desse modo, cada morança era presidida por uma matriarca e integrada por suas filhas, a qual, em sua habitação, ou sarsunuma específica, criava seus filhos, que ficavam sob sua responsabilidade até chegarem à puberdade, quando então os meninos passavam ao cuidado educacional de um tio irmão da mãe.

Essa estrutura é fundamental para entender a formação física das tabancas. Como havia uma circulação intensa dentro das tabancas, era 
conveniente que as moranças ficassem próximas umas das outras. Este fato favorecia a formação das aldeias e fazia com que cada matriarca tivesse um controle rígido de suas filhas, o que conferia considerável autoridade às mulheres idosas que, por sinal, se destacavam como sacerdotisas (mães de santo).

Mais adiante, a mesma concepção também favorecia a formação das cidades (figuras 21 e 22). Para não abrir mão da organização tribal, cada cidade era formada por bairros, os mисеques próprios de cada tribo, rigidamente separados entre si por muros circundantes, com uma única entrada que levava a uma praça central, denominada posoban, que se constituía em espaço sóciopolítico e de convivência dos integrantes da tribo. Além disso, cada muceque era rigidamente separado dos demais por amplas avenidas utilizadas como áreas de comércio onde cada grupo vendia produtos artesanais no qual era especializado.

Figuras 21 e 22 - Aspectos das cidades de Cutiala, no Mali e de Cano, na Nigéria
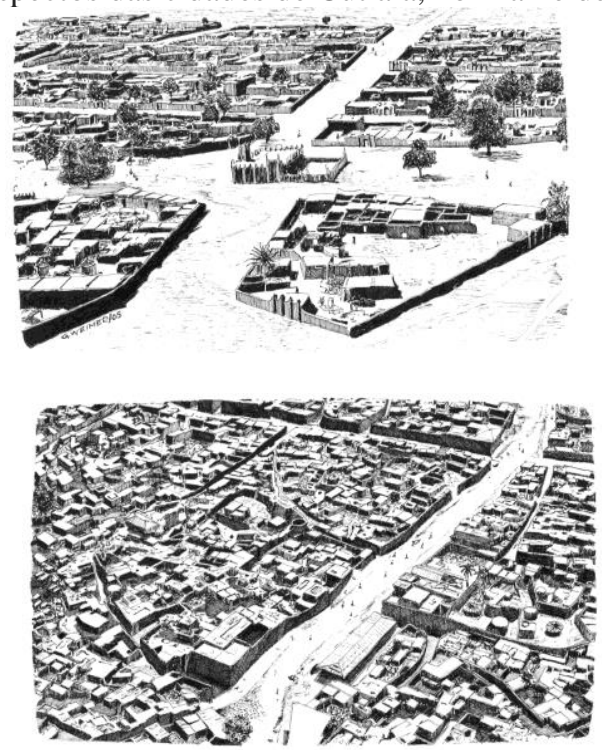

Fonte: Weimer (2014, p. 104; p. 106).

\section{Os afro-brasileiros}

As principais características das concepções espaciais praticadas em solo africano se constituíram nos componentes com que os afro-brasileiros vieram a se confrontar quando foram inseridos na sociedade escravocrata colonial 
brasileira. As diversas contradições a que foram expostos se materializaram de modos muito diversos, dependendo das condições em que se deu essa inserção.

Quando as concepções se sobrepunham às dos conquistadores e/ou indígenas, as mesmas eram enfatizadas. Isso aconteceu, por exemplo, no conceito de que o centro da vila ou cidade deveria ser uma praça acessada por meio de uma via direta, aqui denominada de Rua Direita, enquanto a Praça da Matriz correspondia à praça central (posoban) das aldeias (quilombos) na África.

Quando havia uma divergência entre conceitos, a alternativa adotada era a solução mais conveniente. A incorporação das varandas à arquitetura brasileira foi bem mais ampla que a utilização dos alpendres, em Portugal, e com as coberturas das construções aconteceu algo semelhante. Entre os bantos, a solução majoritária era o tipo cone-sobre-cilindro ou semiesfera-sobre-cilindro, desconhecida em Portugal. Aqui, o partido adotado foi o que era hegemônico na cultura portuguesa, mas pouco empregado na África, que era a casa de cumeeira, que entre os africanos era denominada de mukambu, comum ao norte de Angola. A arquitetura banto se caracterizava pela ausência de janelas, em confronto com a arquitetura do colonizador, que as empregava em quantidade. Desse modo, os escravizados adotaram poucas janelas e de reduzidas dimensões, providas de barras verticais de madeira encaixadas no peitoril e na verga. Esta solução tem sido atribuída equivocadamente à cultura ibérica, quando, de fato, era hegemônica na arquitetura sudanesa. $\mathrm{Na}$ arquitetura ibérica, as guarnições das aberturas eram gradis de ferro colocados no lado externo das paredes.

Havendo divergências de conceitos, afloravam os conflitos. Um exemplo desse tipo de oposição vem se processando, de longa data, na região dos chamados Alagados, na Ponta de Itapagipe, em Salvador. Numa baia de águas raras, a população negra resolveu se estabelecer num conglomerado sobre palafitas, conforme as formas tradicionais da cultura sudanesa. Segundo os conceitos europeus, construções lacustres são altamente condenáveis, quanto vergonhosas. Por isso, a Prefeitura de Salvador tratou de contratar um dos mais conceituados arquitetos da elite carioca para sanear o local, que propôs a 
construção de magníficos prédios de concreto armado no local, depois de ser devidamente aterrado.

Tal solução extrapolou os orçamentos da municipalidade e o projeto teve que ser arquivado. Para compensar o prejuízo, arquitetos locais propuseram um loteamento do aterro com lotes mínimos, ruelas estreitas e casas minúsculas. As obras ainda não haviam sido concluídas, quando os moradores locais passaram a gravar estacas dentro da água para construir suas palafitas habitacionais.

Com a expansão dessas construções, a Prefeitura viu-se constrangida a resolver o que considerava um desvario. Novamente foram contratados arquitetos de renome que, mais uma vez, propuseram novo aterro, mas complementado com a inclusão de atrativos sociais em locais opostos às margens das águas. Todavia, nem o centro culturas, nem as obras congêneres construídas, foram suficientes para minorar o ímpeto da gravação de novas estacas e de construção de novas palafitas. Eis um resumo de uma longa disputa que vem se arrastando há muito e que está longe de ser encerrada, ao que tudo indica.

O trabalho braçal era tido como desprezível para os conquistadores e delegado aos escravizados, que se utilizavam dos conhecimentos que possuíam. Desse modo, as técnicas construtivas hegemônicas na Colônia passaram a ser as taipas leves, de origem africana. As taipas leves são paredes de trançado de varas recobertas das taipas pesadas, que consistiam em paredes grossas de barro, com mais de $50 \mathrm{~cm}$ de espessura, apoiadas entre duas tábuas que eram removidas depois de concluída a compactação.

Outro exemplo de adaptação foi o das coberturas. Na África, o material preferencial era a palha, que tinha a vantagem de se constituir num bom isolante térmico, mas apresentava o inconveniente de ter de ser refeita de tempos em tempos devido ao apodrecimento. Os conquistadores trouxeram a técnica de cobrir as construções com telhas cerâmicas, que não tinham um poder de isolante tão eficiente como a palha, mas, em compensação, com duração quase ilimitada. Por isso, as últimas acabaram por serem preferidas.

Todavia, essa aceitação não foi total. Aqui crescia uma palmeira que produzia uma fibra resinosa, muito resistente e de longa duração, chamada de 
piaçaba ou piaçava, de consistência semelhante a certos tipos de plásticos, que acabou por se impor nas regiões em que crescia.

As moradias africanas eram compostas por várias construções monofuncionais, enquanto as dos colonizadores eram multifuncionais. A opção que acabou se impondo entre os afrodescendentes foi a construção de habitações preferencialmente plurifuncionais, com valorização do trabalho ao ar livre, do modo africano. Essas moradias eram destinadas aos casados e eram formadas por duas (ou três) dependências. Tanto nessas casas como nas senzalas, dormiase em esteiras de palha sobre o chão batido, mas o costume indígena de dormir em redes suspensas foi uma inovação bem aceita.

O espaço da cozinha se organizava em torno de um fogão, que era formado por uma pequena plataforma de terra em que eram fixadas três pedras apontadas, sobre as quais era apoiada uma panela de barro na qual era preparado o alimento, de forma idêntica à da África. Para a refeição, a panela era colocada sobre uma esteira estendida no chão e os comensais se agrupavam ao seu redor e se serviam diretamente da panela. Normalmente, a carne e outras iguarias eram envolvidas com farinha de mandioca, a farinha da terra, formando uma espécie de bolinho amassado nas mãos que iam sendo mastigado enquanto era preparado outro. Esse costume foi adotado pela elite, mesmo quando dispunham de talheres, conforme relatos de inúmeros viajantes.

Os solteiros se abrigavam em habitações coletivas africanas chamadas de senzalas, adaptações das sanzalas praticadas entre Cabinda e Gabão. As senzalas eram compostas por vários dormitórios e tinham uma cozinha coletiva numa de suas extremidades, onde a cozinheira servia o alimento numa tigela de barro para cada comensal. Embora seja este o padrão divulgado na literatura brasileira para as senzalas, trata-se do formato característico dos latifúndios açucareiros.

$\mathrm{Na}$ medida em que a escravidão foi sendo substituída pelo trabalho livre, especialmente a partir da assim chamada abolição da escravatura, muitos negros libertos se estabeleceram em zonas pantanosas, como era tradição em algumas de suas culturas originais, para espanto das elites governamentais. Seja por falta de opção na localização de suas moradias, ou movidos pela preservação 
de suas tradições, esse tipo de habitação se tornou comum nas regiões costeiras do País (figuras 23 e 24).

Figuras 23 e 24 - Palafitas como alternativas de moradia para escravos libertos

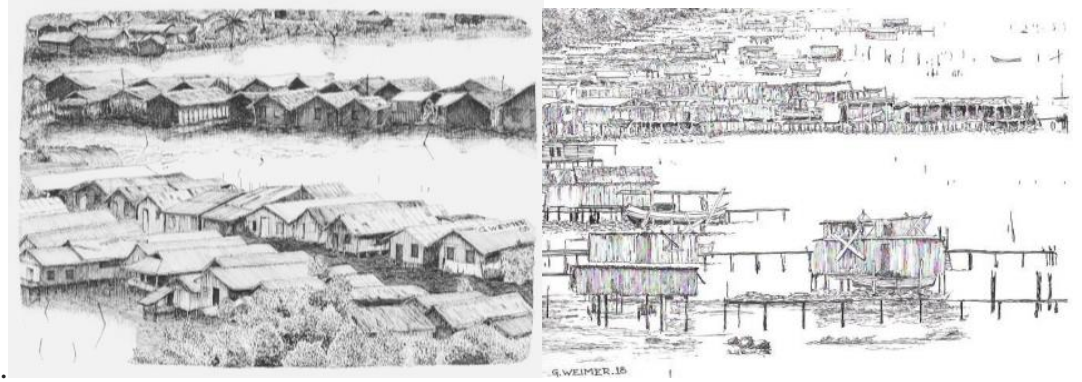

Fonte: Weimer (2014, p. 264).

Nota: À esquerda, o bairro Jansen, de São Luís, Maranhão, com suas casas sobre palafitas e à direita apalafitada em assentamento de pescadores em Laguna, Santa Catarina.

Nas regiões de mineração o trabalho exigia uma fiscalização mais acurada, o que levou a uma maior aproximação entre o dono do garimpo, ou seus prepostos, e os lavadores/catadores. Com isso, surgiu uma nova forma de habitação que era a enxovia (figuras 25 e 26), que consistia no abrigo dos escravos nos porões das casas senhoriais. Era também dividida em vários dormitórios e complementada por uma cozinha, dita de fora para diferenciá-la da de dentro, onde eram preparados os alimentos do senhorio. Evidentemente, aqui não se trata de uma arquitetura africana, mas sua citação decorre do fato de ter servido de habitação de escravos (SAINT-HILAIRE, 1973). Na figura 25, observa-se o pátio interno de uma casa senhorial em Sabará, Minas Gerais, onde o acesso às enxovias era feito através das portas em baixo, à esquerda da imagem (GRAHAM, 1990; POHL, 1976; RIBEYROLLES, 1976).

Na figura 26, apresenta-se o Solar do Alexandrino de Alencar, em Rio Pardo, Rio Grande do Sul, onde as enxovias consistiam num longo corredor nos fundos do porão, que o atravessava de fora a fora e cujas únicas aberturas de ventilação eram duas seteiras em cada extremidade. 


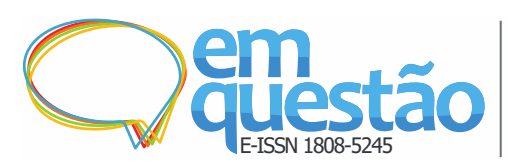

Figuras 25 e 26 - As enxovias

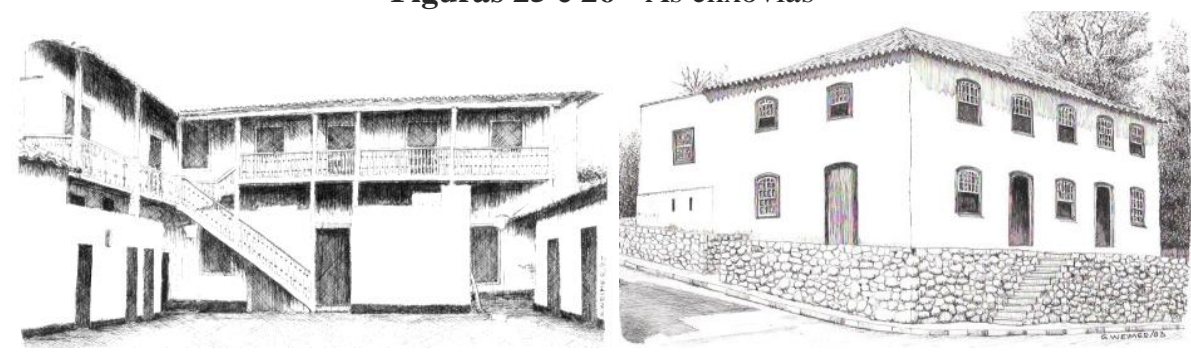

Fonte: Weimer (2014, p. 211; p. 214).

É comum ocorrerem equívocos com o chamado saneamento das favelas e com as construções populares (BURTON, 1976). Partindo de concepções europeias, estão sendo construídos novos assentamentos como os quais se pretende conferir melhores condições de vida a seus habitantes. Estas boas intenções, no entanto, têm sido frustradas na medida em que esses assentamentos vão se transformando, rapidamente, em bairros marginalizados que são dominados por organizações que mantém o domínio através da violência.

Isso decorre de diversos fatores, mas, no que concerne à arquitetura, em nosso entender, é causado pelo desconhecimento e desrespeito à tradição africana da organização das cidades. Hoje as favelas se transformaram em cidades-satélites que vem sendo chamadas de complexos e são divididas em comunidades, separadas entre si por vias de trânsito, acidentes naturais ou por terrenos vazios ou arborizados. Essa organização reflete perfeitamente a forma de organização das cidades africanas e que, portanto, deveria ser mantida e servir de diretriz básica para as intervenções, visando o melhoramento das condições sanitárias, de circulação e de habitabilidade.

É sabido que as regiões pioneiras no fornecimento de escravos foram as costas africanas ocupadas pelos bantos que, dado o seu modo de vida, preferiam morar em epatas, unidades afastadas entre si. Por isso, a formação de aldeias é muito tímida e o espaço interno das aldeias é rarefeito. Ora, esta é a forma mais corrente da ocupação humana do sertão nordestino, em cujos vilarejos é característico o comercio ao ar livre nas feiras dos finais de semana. Trata-se de uma forma comum da organização dos quilombos africanos, que demonstra o quão próximo da África se encontram vastas regiões do Brasil. 


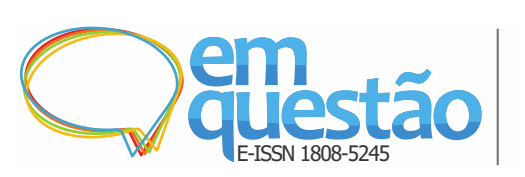

\section{Arquitetura popular afro-brasileira}

Gunter Weimer

O fluxo de imigração africana no Brasil foi muito expressivo durante o Império, quando começou a se desenvolver uma progressiva migração da população do campo para as cidades. Isso se refletiu nas cidades mais importantes do País, que absorveram grande contingente dos sudaneses. Disso decorreu que a prática do culto africano mais divulgado é o dessa matriz, enquanto o de matriz banto se estabeleceu em comunidades menores e mais isoladas (AZEVEDO, 1980).

No plano religioso também deve ser relevada a importância das mães de santo, que exercem grande influência nas comunidades negras. Os planos de melhoramento das habitações deveriam prestar muita atenção a essas lideranças na formulação de seus projetos e na correta localização dos terreiros.

Um assunto ainda menos estudado foi a conquista do interior do Brasil em seus primórdios, sendo conhecidas as incursões dos bandeirantes em suas caça aos indígenas e na procura de preciosidades, bem como as entradas realizadas por ordem governamental, sob o comando de militares (SAINTHILAIRE, 1976; FLETCHER, 1941; ORBIGNY, 1975). É sabido que desses empreendimentos resultou a formação de muitos povoados majoritariamente formados por negros e mestiços que monopolizavam as construções ao modo africano.

Igualmente tem sido pouco investigada a ocupação do interior pelas fazendas de gado, processo que começou com a chegada do primeiro Governador Geral quando um parente seu, provido de ordenação real, obteve o privilégio da criação do gado que havia sido trazido na ocasião. A saga dos Garcia d'Ávila e a incorporação de vastos territórios que iam sendo apropriados com a expansão livre do gado pelo interior, resultaram na formação de um latifúndio que superava em área a de muitos países europeus. Como esse território adquiriu dimensões gigantescas e impossíveis de serem administradas a partir do castelo da família localizado em Mata de São João, nas proximidades de Salvador, o latifúndio acabou por ser ocupado por posseiros cujos agregados, negros e mestiços, que produziram uma arquitetura que Gustavo Barroso descreveu na seguinte forma:

Em Questão, Porto Alegre, v. 26, p. 291-316, Edição Especial Dossiê Patrimônio e Culturas Tradicionais, 2020 


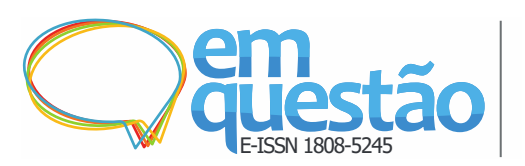

Todas as casas sertanejas são humildes, quer sejam de palha só ou de palha e taipa, quer sejam de taipa e telha. São baixas, rebocadas rudemente, rodeados de alpendres, paredes caiadas e nuas... São sempre edificadas numa elevação do terreno, batidas de vento e do sol, comum amplo e limpo terreira na frente, atrás um quintalejo cercado, um retalho de terra, onde se erguem canteiros rudes. Sua construção é segura e forte... São de tamanho regular com quatro abas de telhado, portas pesadas de umburana, rijos sabiás madeirando as paredes, unidos por finas ripas de morroró seguras de lios rachados e na taipa é o barro atirado por cima às bofetadas, toscamente. As paredes dos alpendres são cobertas de pregos e forquilhas onde o matuto arma redes para dormir e descansar, pendura arreios e todos os apetrechos necessários aos cavalos e ao gado. (BARROSO, 1930, p. 191)

Os matutos eram mestiços tri-híbridos, também herdeiros da cultura afrobrasileira como, aliás, indica a descrição antes referida. Em nossas andanças pelo sertão nordestino, verificamos que as construções de taipa leve, janelas pequenas e cobertura de telhas canal são hegemônicas e que muito bem representa a formação mestiça de seus habitantes (AVÉ-LALLEMANT, 1961).

Sobre as habitações dos escravos no Rio Grande do Sul temos dados mais concretos. Desde o início da ocupação lusitana do território, a presença de negro foi marcante. Em certas regiões de Porto Alegre, os afrodescendentes constituíam a maioria da população, situação que mudou drasticamente no II Império, quando houve uma venda massiva de cativos para as fazendas de café do Vale do Parnaíba, e depois para São Paulo.

Nas fazendas e estâncias ganadeiras da campanha rio-grandense havia uma divisão do trabalho entre os escravos negros e os gaudérios ou gaúchos, que eram os peões, homens livres, descendentes de castelhanos e lusos, que se estabeleceram em terras indígenas chamadas de Campos Neutrais. Como não havia cercas entre as sesmarias, os gaúchos eram encarregados de vigiar os rebanhos de gado para não ultrapassassem as divisas. As suas habitações eram chatões (figura 27), casas de paredes de torrões e cobertas de capim santa-fé. 


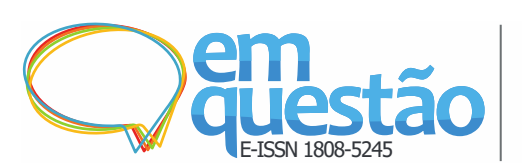

\section{Arquitetura popular afro-brasileira}

Gunter Weimer

Figura 27 - Um chatão da Campanha Sul-rio-grandense

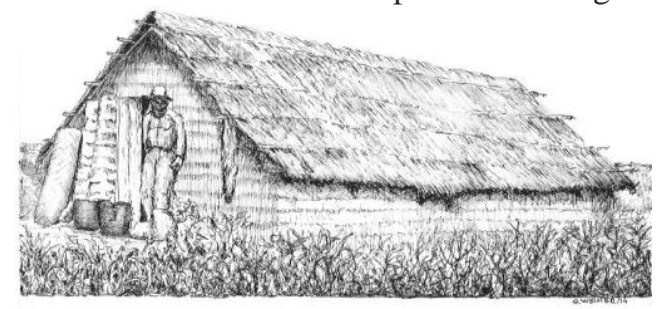

Fonte: Elaborada pelo autor.

As casas de fazenda eram organizadas em torno de um pátio central e a habitação do senhorio ocupava dois lados, em nível pouco elevado e separado do pátrio por um avarandado. Um dos lados dessa habitação era destinado aos serviços de cozinha, dispensa e copa, e o outro para as dependências da família. Os dois lados restantes do pátio eram ocupados pelas cafuas, que eram as moradias dos escravos (figuras 28 e 29).

Figuras 28 e 29 - Fazenda da Arvorezinha (elevação e planta), em Camaquã, RS

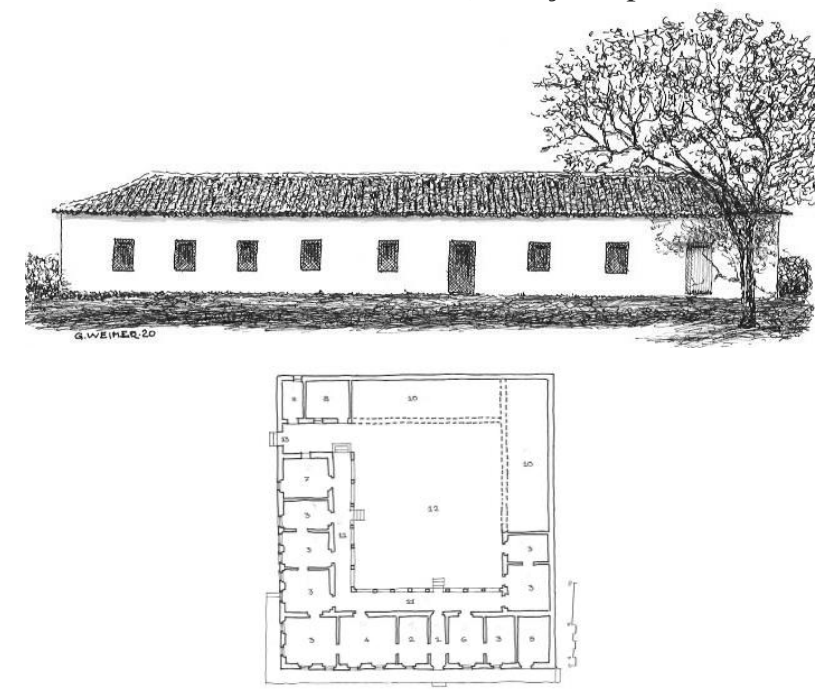

Fonte : Elaboradas pelo autor.

Nos Campos Neutrais não havia escravidão e a abolição foi extinta precocemente no Uruguai, e, em decorrência, os escravos se sentiam atraídos a se evadir para além das fronteiras, o que exigia um rígido controle, o que se refletiu na construção de um monumental portão de entrada a esses pátios.

Quando foi abolida a escravidão, os negros se reagruparam em quilombos, muitos dos quais ainda se mantêm até hoje, espalhados pela 
Campanha, onde puderam recriar sua arquitetura ancestral (figuras 30 e 31), por vezes influenciada por procedimentos de tradição lusa.

Figura 30 - Uma cubata de taipa de mão em solo rio-grandense, interior de Bagé

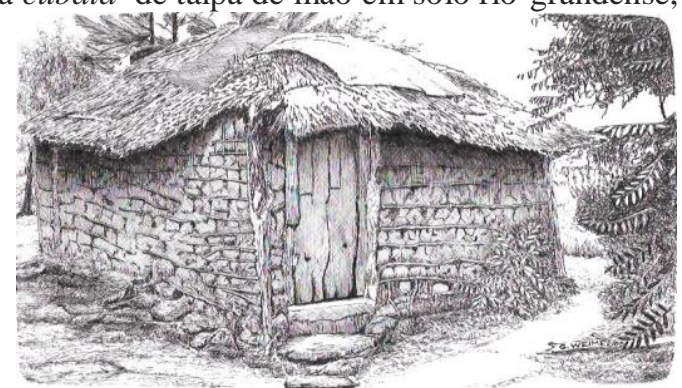

Fonte: Weimer (2014, p. 238).

Figura 31 - Uma cubata de adobe, interior de Bagé

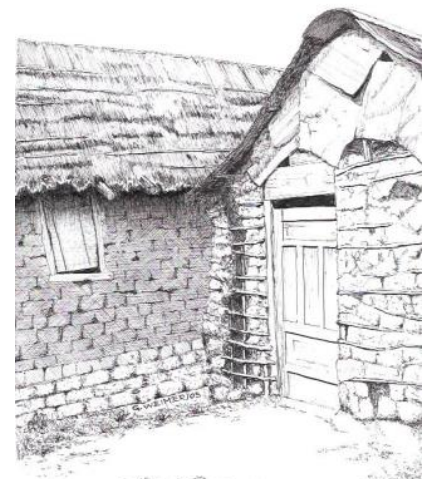

Fonte: Weimer (2014, p. 238).

Esse contingenciamento não existia nas fazendas que ficavam longe da fronteira. Assim, o trabalho de vigilância do rebanho de gado frequentemente era repassado aos negros que eram de confiança dos senhores. Suas habitações foram referidas por Saint-Hilaire nos seguintes termos "Pequenas casas cercadas de cultura, defendidas do gado por valas profundas guarnecidas de cactos em seus bordos" (SAINT-HILAIRE, 1974, p. 46), ou ainda,

Mais além se estendem vastos gramados semeados de espinheiros, grupos de árvores e fileiras de arbustos copados que desenham contornos irregulares de um grande número de sebes. (SAINTHILAIRE, 1974, p. 41).

Sem se referir explicitamente que se tratava de casas de negros, o autor assinala que:

Em Questão, Porto Alegre, v. 26, p. 291-316, Edição Especial Dossiê Patrimônio e Culturas Tradicionais, 2020 doi: http://dx.doi.org/10.19132/1808-5245260.291-316 
[...] a região (de Porto Alegre) é povoada de casas pequenas, porém bem conservadas e construídas sobre eminências do terreno. Junto a cada casa existe um grupo de frondosas laranjeiras (nota 8), no momento pejadas (nota 9) de magníficos frutos e, nas vizinhanças, vêem-se plantações de mandioca cercadas de valas profundas, e limitadas no lado interno por uma fileira de cactáceas. (SAINTHILAIRE, 1974, p. 29)

Ora, tratam-se estas de exatas descrições de epatas dos bantos. É difícil encontrar alguma iconografia dessas habitações, mas elas devem se assemelhar às fotos muito antigas, da periferia da cidade.

Em nossas andanças pelo Brasil, fomos surpreendidos diversas vezes por encontrar fatos inesperados, sendo que o maior deles aconteceu no Acre. É sabido que na Amazônia as influências africanas são pouco relevantes devido à formação primordial que privilegiou a arquitetura de origem lusa e nativa. Em visita a um aldeamento em floresta próximo a Rio Branco, verificamos que as habitações dos seringueiros, denominadas de tapiri, eram construídas sobre palafitas, com paredes de galhos afixados de modo a permitir ampla ventilação cruzada, espessa cobertura de folhas de palmeira, pisos de troncos fendidos de palmeiras e recobertos com uma manta de cerne de palmeira batido para homogeneizar recobrir eventuais desnivelamentos da superfície, numa reedição das casas de pântanos dos sudaneses (FLORENCE, 1977). Ainda que apresentassem algumas divergências funcionais, como o emprego de grande parte da moradia na forma de um avarandado que ocupava cerca da metade da superfície da construção, o que não era encontrado em terras sudanesas, não podia haver dúvidas sobre sua origem africana (figura 32).

Figura 32 - Um tapiri de seringueiro amazônico

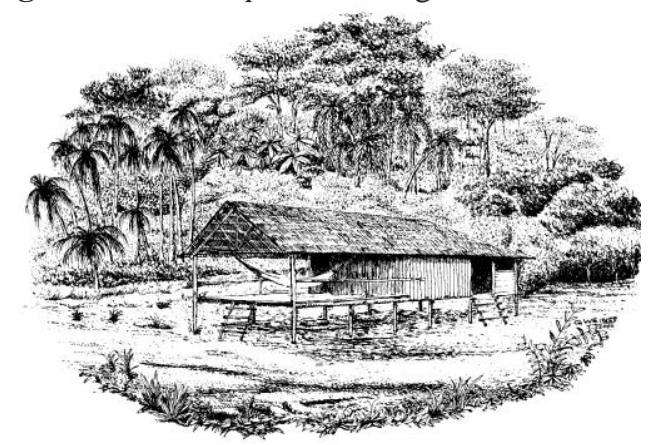

Fonte: Weimer (2012, p. 60).

Em Questão, Porto Alegre, v. 26, p. 291-316, Edição Especial Dossiê Patrimônio e Culturas Tradicionais, 2020 doi: http://dx.doi.org/10.19132/1808-5245260.291-316 
É muito intrigante a forma como estas técnicas construtivas chegaram ao extremo oeste do País, uma vez que não temos encontrado referências sobre seu emprego em outras regiões do território nacional. Supomos que essas técnicas tenham sido levadas para a Amazônia pelos chamados soldados da borracha, que, em duas épocas diferentes foram trazidos do Nordeste para servirem de coletores do látex, uma no auge do ciclo da borracha e outra, nas vésperas da II Guerra Mundial. Mesmo assim, esta revivescência é surpreendente, posto que essas migrações aconteceram muito tempo depois de terem sido encerradas as atividades de importação de mão de obra cativa para o Brasil. As construções que mais se aproximam delas são as que dos manguezais da costa brasileira, com as quais mantêm somente algumas semelhanças.

\section{Considerações finais}

A arquitetura africana, à semelhança do que acontece em outras culturas, teve uma versão palaciana e outra popular. A forma como se procedeu na vinda da mão de obra escravizada para o Brasil, fez com que somente a segunda versão fosse praticada neste lado do Atlântico. Ainda que a população africana se dividisse em múltiplas culturas, razões diversas levaram a que quase exclusivamente fossem trazidas pessoas das culturas banto e sudanesa. Apesar das imposições decorrentes da escravidão, os preceitos sociais e o fato de os africanos e seus descendentes se constituírem na maioria da população, os conceitos e técnicas construtivas se tornaram hegemônicas no nível popular da arquitetura brasileira até o fim da escravidão. Claro está que a confluência de culturas tão diferentes como a africana com a reinol e indígena acabou por fomentar uma profunda miscigenação de procedimentos, que nem sempre aconteceram de forma pacífica e que, por vezes, ainda hoje vêm se manifestando em divergências conceituais relevantes.

\section{Referências}

AVÉ-LALLEMANT, Robert Berthold. Viagens pelo norte do Brasil no ano de 1859. Rio de Janeiro: Instituto Nacional do Livro, 1961. v. I e II. 
AZEVEDO, Paulo Ormindo David de. Inventário de Proteção do Acervo Cultural da Bahia. IV Volumes. Salvador: Governo do Estado, 1980.

BARDOU, Patrick; ARZOUMANIAN, Varoujan. Arquitecturas de adobe. Barcelona: Gili, 1979.

BARROSO, Gustavo. Terra de Sol: natureza e costumes do norte. Rio de Janeiro: Livraria Francisco Alves, 1930.

BURTON. Richard Francis. Viagem do Rio de Janeiro a Morro Velho. Belo Horizonte: Itatiaia; São Paulo: EdUSP, 1976.

FLORENCE, Hercules. Viagem fluvial do Tietê ao Amazonas. São Paulo: Cultrix, EdUSP, 1977.

FLETCHER, James Cooley; KIDDER, Daniel Parich. O Brasil e os Brasileiros. São Paulo: Nacional, 1941.

GRAHAM, Maria. Diário de uma viagem ao Brasil. Belo Horizonte: Itatiaia; São Paulo: EdUSP, 1990.

KARASCH, Mary. Slaves live in Rio de Janeiro, 1808-1850. Princeton: Princeton University Press, 1987.

ORBIGNY, Alcide d'. Viagem Pitoresca através do Brasil. Belo Horizonte: Itatiaia; São Paulo: EdUSP, 1975.

POHL, Johann Emanuel. Viagem ao Interior do Brasil. Belo Horizonte: Itatiaia; São Paulo: EdUSP, 1976.

RIBEYROLLES, Charles. Brasil Pitoresco. Vol. II. Belo Horizonte: Itatiaia; São Paulo: EdUSP 1976.

SAINT-HILAIRE, August. Viagem pelo Distrito dos Diamantes e Litoral do Brasil. Belo Horizonte: Itatiaia; São Paulo:EDUSP, 1973.

SAINT-HILAIRE, August. Viagem ao Espírito Santo e Rio doce. Belo Horizonte: Itatiaia; São Paulo: EdUSP, 1974.

SAINT-HILAIRE, August. Viagem à Província de São Paulo. Belo Horizonte: Itatiaia; São Paulo: EDUSP, 1976.

STRÖRIG, Hans Joachim. A aventura das línguas: uma história dos idiomas do mundo. São Paulo: Melhoramentos, 2003.

WEIMER, Gunter. Inter-relações arquitetônicas Brasil África. Discurso de posse como Membro Efetivo do Instituto Histórico e Geográfico do Rio Grande do Sul 28 de maio de 2008.

Em Questão, Porto Alegre, v. 26, p. 291-316, Edição Especial Dossiê Patrimônio e Culturas Tradicionais, 2020 doi: http://dx.doi.org/10.19132/1808-5245260.291-316 
WEIMER, Gunter. Arquitetura popular brasileira. 2.ed. São Paulo: Martins Fontes, 2012.

WEIMER, Gunter. Inter-relações afro-brasileiras na arquitetura. Porto Alegre: EDIPUCRS, 2014.

\title{
Afro-brazilian popular architecture
}

\begin{abstract}
African architecture has a multimillennial history that has not been well studied just now. Only a small part of its great diversity of manifestations had come to Brazil, mainly due to preconception during slave trade. Therefore, only Bantu and Sudanese cultures were brought to Brazil and influenced our popular construction. During colonial period most Brazilian population had African origin and their architecture became hegemonic in popular housing, but with Indian and Portuguese influence. This mechanism resulted in a great adaptation capacity.
\end{abstract}

Keywords: Popular architecture. Afro brasilian architecture. Vernacular architecture.

Recebido: 20/08/2020

Aceito: $31 / 08 / 2020$

\section{Declaração de autoria}

Concepção e elaboração do estudo: Gunter Weimer

Coleta de dados: Gunter Weimer

Análise e discussão de dados: Gunter Weimer

Redação e revisão do manuscrito: Gunter Weimer

Como citar

WEIMER, Gunter. Arquitetura popular afro-brasileira. Em Questão, Porto Alegre, v. 26, p. 291-316, Edição Especial Dossiê Patrimônio e Culturas Tradicionais, 2020. DOI: http://dx.doi.org/10.19132/1808-5245260.291-316 